\title{
Report on First TESLA Window Assembly Test
}

\author{
Ding Sun and Karl Koepke \\ Fermi National Accelerator Laboratory \\ P.O. Box 500, Batavia, Illinois 60510
}

October 1993 


\section{Disclaimer}

This report was prepared as an account of work sponsored by an agency of the United States Government. Neither the United States Government nor any agency thereof, nor any of their employees, makes any warranty, express or implied, or assumes any legal liability or responsibility for the accuracy, completeness, or usefulness of any information, apparatus, product, or process disclosed, or represents that its use would not infringe privately owned rights. Reference herein to any specific commercial product, process, or service by trade name, trademark, manufacturer, or otherwise, does not necessarily constitute or imply its endorsement, recommendation, or favoring by the United States Government or any agency thereof. The views and opinions of authors expressed herein do not necessarily state or reflect those of the United States Government or any agency thereof. 


\title{
REPORT ON FIRST TESLA WINDOW ASSEMBLY TEST
}

\author{
Ding Sun and Karl Koepke
}

\begin{abstract}
s
RF input couplers for the superconducting cavities of the TESLA are under development at DESY and Fermilab. The coaxial part of the Fermilab input coupler has been tested up to $1.7 \mathrm{MW}$ at Fermilab using $805 \mathrm{MHz}$ if power source. The test results, procedure and test setup are described.
\end{abstract}

\section{INTRODUCTION}

TESLA is a proposed $500 \mathrm{GeV}$ center of mass energy $e^{+} e^{-}$linear collider using superconducting niobium if cavities to accelerate the $e^{+} e^{-}$beams. The function of the input coupler for these of cavities is to transmit the if power from the WR650 waveguide at room temperature to the niobium cavities at $1.8 \mathrm{~K}$. There are two ceramic windows in the input coupler (see Fig. 1). One is a cylindrical ceramic window around the door-knob which isolates the pressured waveguide from the high vacuum side of the cold coaxial section which is connected to the cavities. The other is a conical ceramic window in the coaxial section that maintains the ultra clean environment required by the superconducting cavities. The rf power required during normal operation is $200 \mathrm{~kW}$ with $2 \mathrm{~ms}$ pulse length and $10 \mathrm{~Hz}$ repetition rate. The in-situ high power processing of the rf cavities under consideration requires an estimated if power of $1 \mathrm{MW}$ with reduced pulse length and repetition rate.

At present, several factors which may affect the performance of the input coupler are unknown. First, the peak power handling capability of a coupler under vacuum is not known. The peak power handling capability is a function of the maximum electric field and voltage that a coupler can withstand without breakdown. The Kilpatrick criterion [1] is widely used among accelerator physicists as a reference for breakdown limit of metals. However, many groups [2] have reported that the breakdown limit of a very well prepared metal surface can be as much as 5-10 times higher than Kilpatrick criterion (see Fig. 2). On the other hand, the coupler is an engineering part which is much more complicated than a clean metal surface. The coupler consists of metals, connectors, ceramics, bellows, seals and welding joints which may create various mechanisms to trigger a breakdown. Second, multipactor may occur in high 
vacuum rf device which can not be predicted easily due to the complicated geometry of the input coupler. Third, the triple point between the the ceramic surface, inner/outer conductor and vacuum may cause surface flashover. All these unknown factors can be checked experimentally.

The test at the A0 area with the window assembly of the TESLA input coupler is aimed to test some of these factors. Since an of power source at $1.3 \mathrm{GHz}$ and 1 MW power level is not currently available, the A0 klystron is used which operates at $805 \mathrm{MHz}$ instead of $1.3 \mathrm{GHz}$. Due to the difference of the operating frequency, only the coaxial part of the Fermilab TESLA input coupler (TESLA window assembly, see Fig. 1) is tested. Although the multipactor effect strongly depends on the frequency, the results about other factors such as electric breakdown and rf power dissipation in ceramic at $805 \mathrm{MHz}$ can be used reasonably to estimate these factors at $1.3 \mathrm{GHz}$.

At the time this memo is written, four tests have been completed and the fifth is in progress. The test with the coaxial window assembly is the fourth test (test 4 ). This memo mainly reports about test 4 . The results of three previous tests are also included.

\section{TEST SETUP}

As shown in Fig. 3 , the test setup consists of two straight $31 / 8$ inch coaxial sections (12 inches long) with 4 rf probes on each section, two coaxial elbows, two coaxial transition tapers to match the test devices to the coaxial lines, two WR975 waveguide - $31 / 8$ inch coaxial line couplers (will be referred as waveguide couplers in the following) and two waveguide windows. The waveguide windows (not shown in Fig. 3) are connected to the waveguide couplers. The rf power is transported from a $12 \mathrm{MW} 805 \mathrm{MHz}$ Klystron of Fermilab LINAC upgrade to the test area with WR975 waveguide, enters the test system through the first waveguide window and coupler, leaves the system through the second waveguide coupler and window, and ends at an rf load. The rf power levels are measured through two directional couplers. One is located before the first waveguide window, the other is between the second waveguide window and the load. The forward power signals from the two directional couplers are used to monitor the power entering and exiting the system. The reflected power signals from the first directional coupler are used to monitor the reflected power from the system.

All Teflon spacers in the coaxial line sections and elbows have been removed. This eliminates the possibility of sparks due to the surface of the Teflon and triple points between Teflon spacer, outer/inner conductor and vacuum. The waveguide couplers and waveguide windows are coated with thin Ti films to prevent electron multipactor. 
There are four turbo pumps connected directly to the test setup to achieve the required high vacuum of $\sim 10^{-7}$ torr. Two $160 \mathrm{l} / \mathrm{s}$ turbo pumps are connected to the coaxial lines and two $28 \mathrm{l} / \mathrm{s}$ turbo pumps are connected to the waveguide couplers. There are two ion gauges monitoring the vacuum in the coaxial line and two other ion gauges monitoring the vacuum in the waveguide couplers. Viton O-rings are used as seals between the two waveguide windows and the two waveguide couplers, and indium is used as a seal between the ceramic and the metal walls of one of the waveguide windows. Because of these seals, the waveguide windows were not baked. The ceramic surfaces outgassed heavily during pumpdown. However, the two $281 / \mathrm{s}$ turbo pumps can effectively ensure the designed vacuum $\left(\sim 10^{-7}\right.$ torr $)$ near the ceramic surface. Two residual gas analyzers are used to monitor the gas constituents during pumpdown and test.

There are 7 glass windows with 7 photomultipliers in the test setup to monitor light signals. Four of them are located at different positions of the coax line region. Two of them monitor the waveguide coupler regions. There is another mini glass window with a photomultiplier on the test device which monitors the light signal in the area near the conical window. During tests, only four photomultipliers are simultaneously used due to the limited number of available high voltage power supplies and data collection channels. The signals from the photomultipliers are used together with the ion gauges to monitor the conditioning process and to locate the region where the sparks occur, if any. The photomultipliers are relatively calibrated in a way that their output intensity are measured when they are put at the same position alternatively so that they face the same source of a light.

The temperature of the conical ceramic window is monitored by an infrared detector (Dexter Model 2M) through a mini $\mathrm{KBr}$ window (see Fig. 1). Two type $\mathrm{E}$ thermocouples are used to monitor the temperature change of the outer conductor at the conical window region. The temperature gradient between the ceramic and the outer conductor may be used to determine if there is extra heating due to multipacting or other detrimental processes in addition to the of power deposition in the ceramics.

A VME digitizer board ( $1 \mathrm{MHz}$ sampling rate) is used to collect the data. There are 8 channels which can store $64 \mathrm{~K}$ samples per channel. The digitizer board is triggered at the beginning of each if pulse and stops at the end of the pulse. The data are sent to a SUN workstation every 15 seconds for long time data collection. When a reflected signal exceeds a preset threshold, the digitizer board will be triggered by this signal and dumps the data into a 1 Mega byte off-board memory called data stream memory for 15 consecutive rf pulses. These data can be displayed at the local Macintosh computer. During tests, the signals from 4 rf probes and 4 photomultipliers are collected with this quick digitizing system. The other data from 4 ion gauges, thermocouples and infrared detector are also collected every 15 seconds through the 
other digitizer and stored in the SUN workstation.

The tested window assembly reported in this memo is shown in Fig. 1. One side of this assembly is a $6 \mathrm{~cm}$ coaxial line and the other side is a $4 \mathrm{~cm}$ coaxial line. Both sides consist of copper plated stainless tubes and bellows as outer and inner conductors. The conical ceramic window is at middle. The window assembly was baked at $200{ }^{\circ} \mathrm{C}$ for about 24 hours under vacuum, but exposed to atmosphere again during assembling.

\section{TEST PROCEDURE}

After the test system was assembled, the SWR and transmission of the system were measured with a network analyzer. The SWR of the test system with the window assembly (test 4 ) is 1.24 , while the SWR in previous tests using stainless steel bellows as test devices were below 1.10 .

Before conditioning, the system was first pumped down to the pressure of $2.8 \times 10^{-7}$ torr. The Conditioning process is as follows. The if power started at very low level and is increased by a small amount step by step. The amount of power increase at each step is determined by the pressure increase which must not exceed a chosen level. In test 4 , this level was chosen as $\sim 2 \times 10^{-6}$ torr at power bellow $300 \mathrm{~kW}$ and $\sim 1 \times 10^{-6}$ torr at power levels above $300 \mathrm{~kW}$. After each power increase, the rf power is kept at that level until the pressure gradually drop back to about $2 \sim 5 \times 10^{-7}$ torr. At this pressure level the power is increased again.

For test 4, the total conditioning process to reach $1.3 \mathrm{MW}$ power level took about 51 hours including 21 hours overnight operation at constant low power levels of 20 $\mathrm{kW}$ and $100 \mathrm{~kW}$. The starting rf power was $3.6 \mathrm{~kW}$ with pulse length of $120 \mu$ s and repetition rate of $15 \mathrm{~Hz}$. At initial stages, the pressure increased drastically whenever the rf power was increased. This limited the power increase to about $1 \sim 3 \mathrm{~kW}$ to keep the pressure below $2.0 \times 10^{-6}$ torr. It took 6 hours to reach $14.4 \mathrm{~kW}$. This is different from the previous tests which tested stainless steel bellows in the outer conductor and without a ceramic. In previous tests, the test could be started at $10 \mathrm{~kW}$ and it took only 2 hours to reach $14.4 \mathrm{~kW}$.

An interesting phenomenon in all four tests is that even the conditioning process had been completed at various power levels, the pressure might still increase at first when the rf power was changed from one power level to another level if the system was operated at the first level for a long time.

After the rf power reached 1.4 MW, the rf power was kept at several levels (1.4 MW, 1.7 MW, 1.3 MW, 1.2 MW, 1.0 MW) until the rf power was tripped off by a big power reflection. This determined the maximum power and the long time high 
power handling capability.

After conditioning and the above tests at high power levels, the of power was decreased step be step. Then the power was increased quickly to ensure the system now can go through fast power increase without trouble and the conditioning process is complete.

\section{RESULTS}

\section{Previous test results}

The first three tests were performed to test bellows in the outer conductor of the coaxial line section. The first and second test used a stainless steel bellow with inner diameter of $8 \mathrm{~cm}$ as outer conductor. The third test used a stainless steel bellows with diameter of $4 \mathrm{~cm}$ as outer conductor.

In all tests including test 4 , the breakdown limit depended on the pulse length. 4 MW could be easily reached with a 0.5 microsecond pulse length in test 2 , while the breakdown frequently occurred above $2 \mathrm{MW}$ with a pulse length of 120 microsecond even after a long time of conditioning. Systematic test on the relation between pulse lengths and breakdown limits have not yet been completed. The peak power results reported in the following are all obtained with pulse lengths of 120 microseconds and repetition rate of $15 \mathrm{~Hz}$.

The peak power reached in test 2 is $2 \mathrm{MW}$ for 7 hours with 1 spark and $1.6 \mathrm{MW}$ for 8 hours with 2 sparks. The peak power reached in test 3 is $1.6 \mathrm{MW}$ for 4 hours without spark. There was no attempt to use $2 \mathrm{MW}$ in test 3 .

\section{Window assembly test results}

The window assembly was continuously tested at $1 \mathrm{MW}$ power level for 17 hours without any abnormal rf reflection. The stable temperature of the conical ceramic window was $35.8^{\circ} \mathrm{C}$ at this power level while the temperature of the outer conductor in the conical window region was $33.1 \sim 34.2$ oC. The room temperature was 25.3 oC. There was no forced cooling for either inner or outer conductors.

When the RF power was increased to above $1.4 \mathrm{MW}$, the rf power tripped off frequently due to large abnormal reflected power which indicated breakdowns. The maximum peak power used was 1.7 MW. The longest dwelling time at this power level was 55 minutes. The longest dwelling time at $1.44 \mathrm{MW}$ power level was 90 minutes.

The photomultiplier signals from photomultiplier No. 3 and No.4 always surged simultaneously when abnormal reflection occurred at aforementioned high power levels 
which indicated that the sparks occurred in the region between photomultiplier No. 3 and No. 4 (see Fig. 4). After testing, the system was opened and visually examined. Several spark traces were found in the transition region of the second waveguide coupler where the coupler transits to the coaxial line (see Fig. 3). This is in agreement with the photomultiplier signals.

Since the breakdowns seen occurred outside the TESLA window assembly region, we have not yet reached the limit of the peak power handling capability of the tested device. Our next effort will be to increase the peak power handling capability of the test setup itself. The second waveguide window, which has spots of the melted indium seal on the ceramic surface, will be replaced.

3. Photomultiplier signals

Detectable photomultiplier signals started at an rf power of $40 \mathrm{~kW}$. From $300 \mathrm{~kW}$ up to $1 \mathrm{MW}$, the signals from photomultiplier No. 1 were -5 -15 Volts (see Fig. 5) which were much larger than the signals in the previous tests when only the stainless steel bellows were used. After the power reached $1 \mathrm{MW}$, a visual observation was performed during the operation. A bright (blue-white) light spot (a crescent of about $1-2 \mathrm{~cm}$ long) was located near the upstream side of the conical ceramic window. A portion of coax line before (upstream) this spot was also illuminated. The observed light versus of power has well defined bands of present and absent light which may be an indication of multipacting. The big signals from photomultiplier No. 1 and No. 2 at these power levels greatly decreased or disappeared after 1 week of operation. The signals from photomultiplier No. 1 is shown in Figure 6.

In all the tests, the signals of the photomultipliers strongly depended on the vacuum, rf power level and duration of the test. Up to now, no repeatable quantitative relationship between the light signals and these conditions has been obtained. This fact reflects the complexity of the photon production mechanisms in the test system.

\section{Conclusion}

The Fermilab designed input coupler window assembly has been tested up to a If power level of $1.7 \mathrm{MW}$. At $1 \mathrm{MW}$, the tested window assembly and test setup has been operated for 17 hours without any breakdown. At power levels above 1.4 MW the breakdown occurred in the region between the coaxial line and the second waveguide-coaxial coupler.

The breakdown limit in all tests depends on the pulse lengths.

The photomultiplier signals recorded by quick digitizing system have been used 
successfully to locate the region of breakdown. The light signals detected by a photomultiplier in our test system may come from different sources and locations which may function at different power levels and different times. For example, we have successfully located one light source for $640 \mathrm{~kW}$ power level at one time and another source at $250 \mathrm{~kW}$ one day later. The location of the light signals is a necessary information for one to determine whether the light signals are related with multipactor effect.

The results from all tests indicate that the existence of light signals (even strong light signals at high power levels) is not necessary to cause abnormal reflection or trigger an electric breakdown.

However, the breakdown is always accompanied by big light signals (in our test system), which have been used to locate where the breakdown region is.

The next task is to increase the high power handling capability of the test setup.

\section{References}

[1] W. P. Kilpatrick, "Criterion for Vacuum Sparking Designed to Include Both rf and dc," Review of Scientific Instruments, Vol. 28, No. 10, pp. 824, 1957.

[2] D. Sun, F. R. Huson and W. W. Mackay, "Voltage Breakdown Test at 473 $\mathrm{MHz}$ " Proceedings of the 1990 Linear Accelerator Conference, Albuquerque, NM, 1990, pp. 216. 


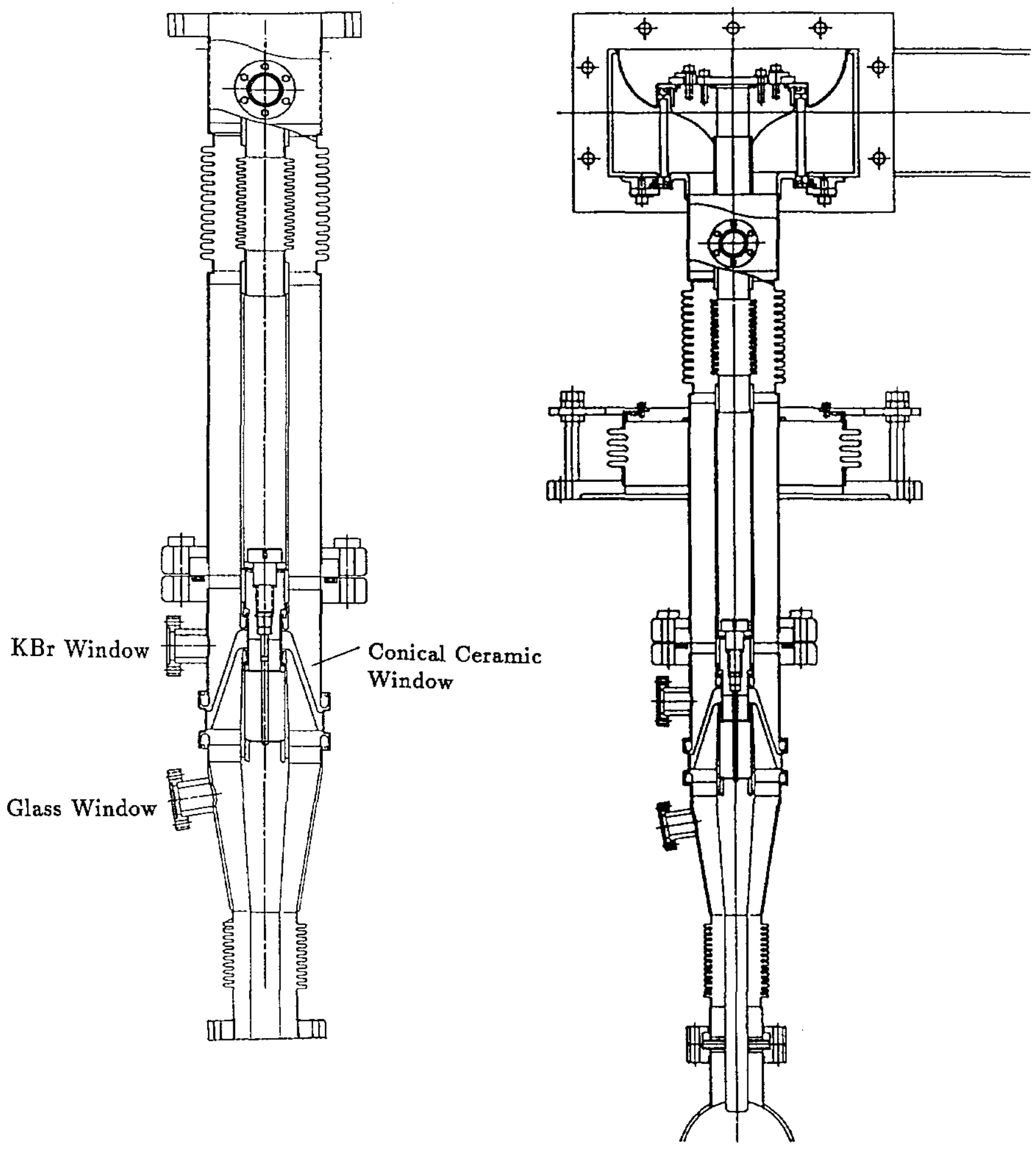

Fig. 1 Input Coupler (right) and Window Assembly (left) 


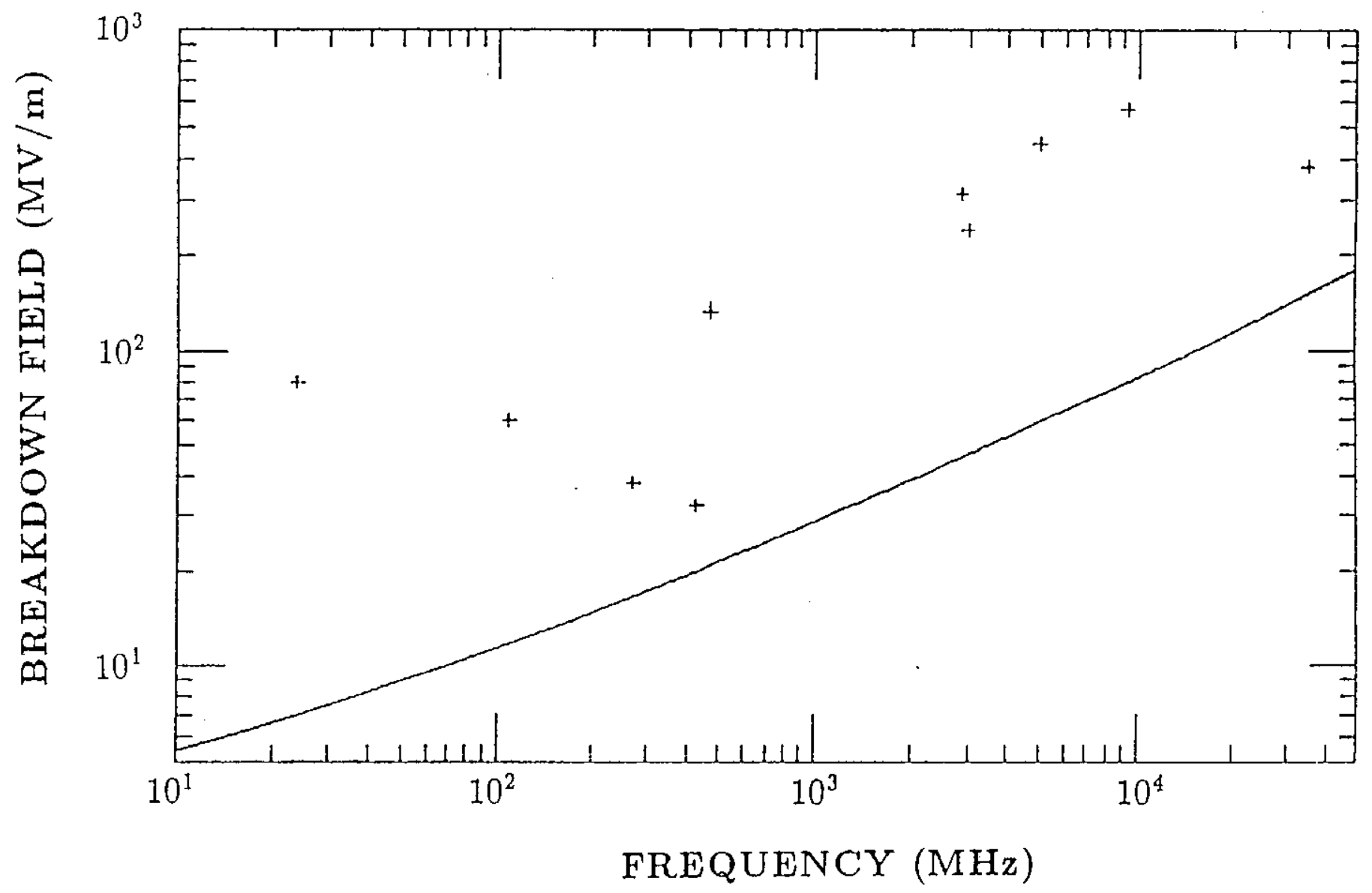

Fig. 2 Experimental Data and Kilpatrick Criterion (solid line) 


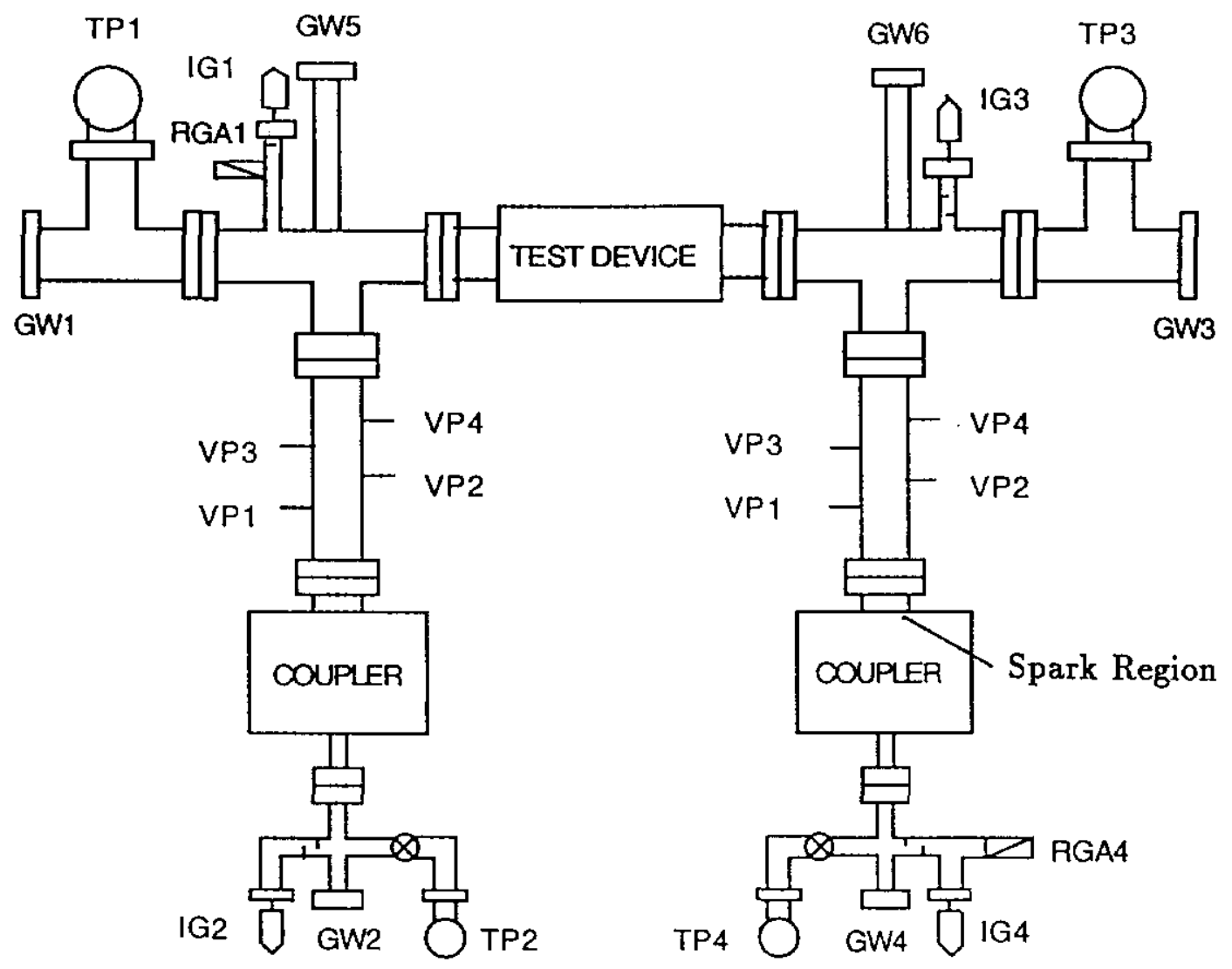

TP: TURBO PUMP

IG: ION GAUGE

RGA: RESIDUAL GAS ANALYZER

GW: GLASS WINDOW

VP: VOLTAGE PROBE

Fig. 3 Test Setup 


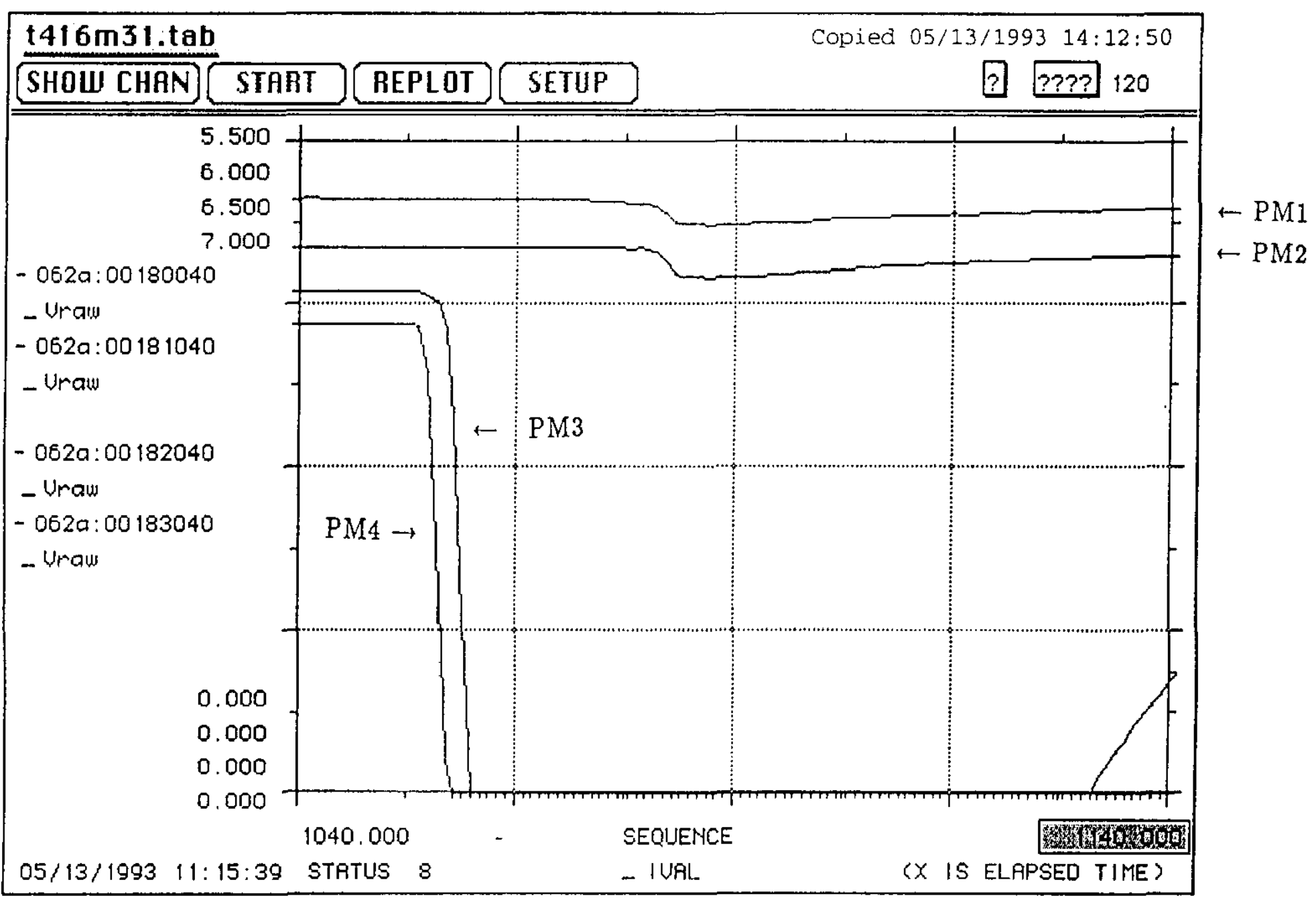

Fig. 4 Photomultiplier Signals at a Breakdown (in sequence of $1 \mathrm{mi}$ cro seconds) 
Fig.5 PHOTOMULTIPLIER (PM \#1) OUTPUT AND RF POWER VERSUS TIME

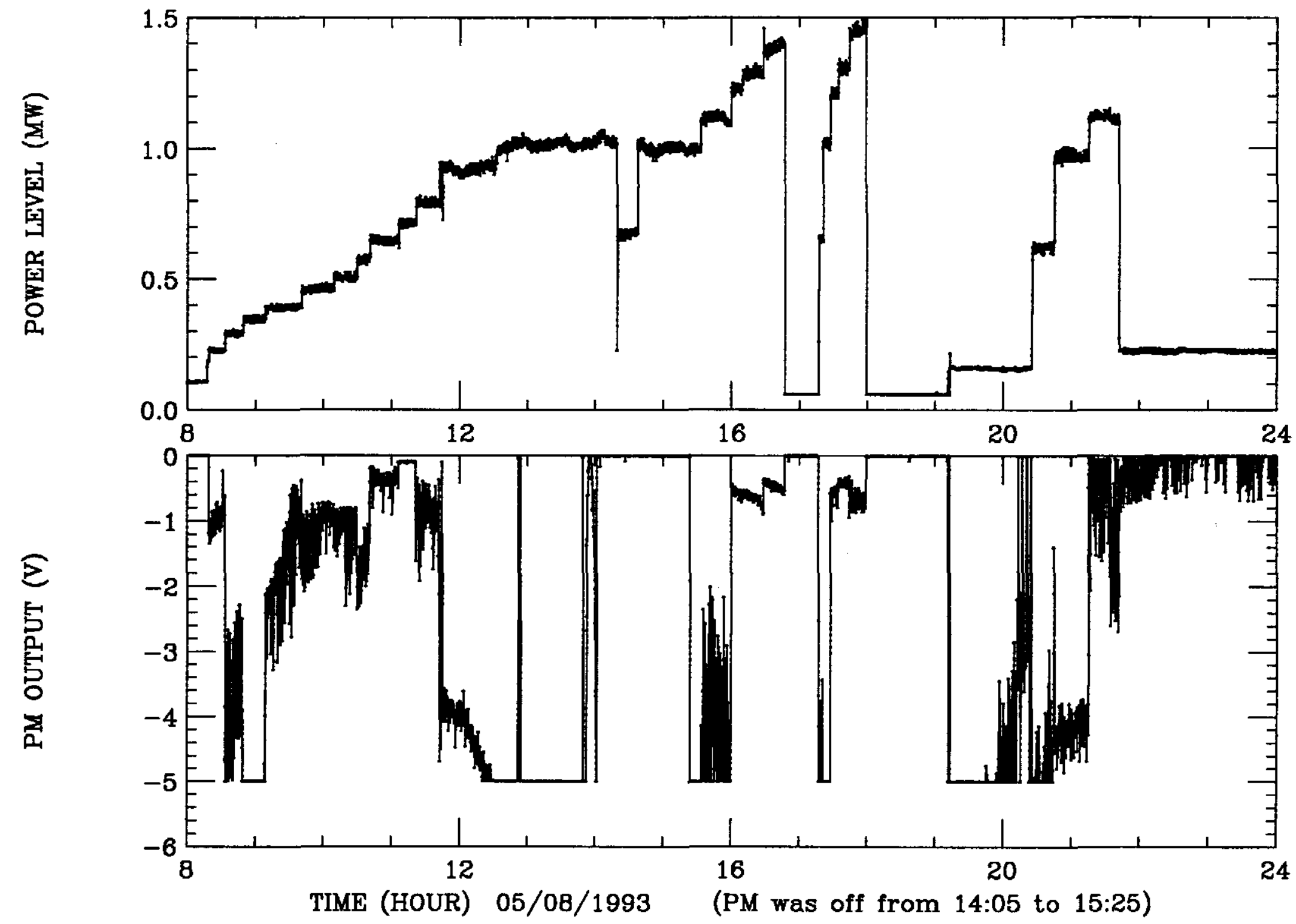


Fig.6 PHOTOMULTIPLIER (PM \#1) OUTPUT AND RF POWER VERSUS TIME

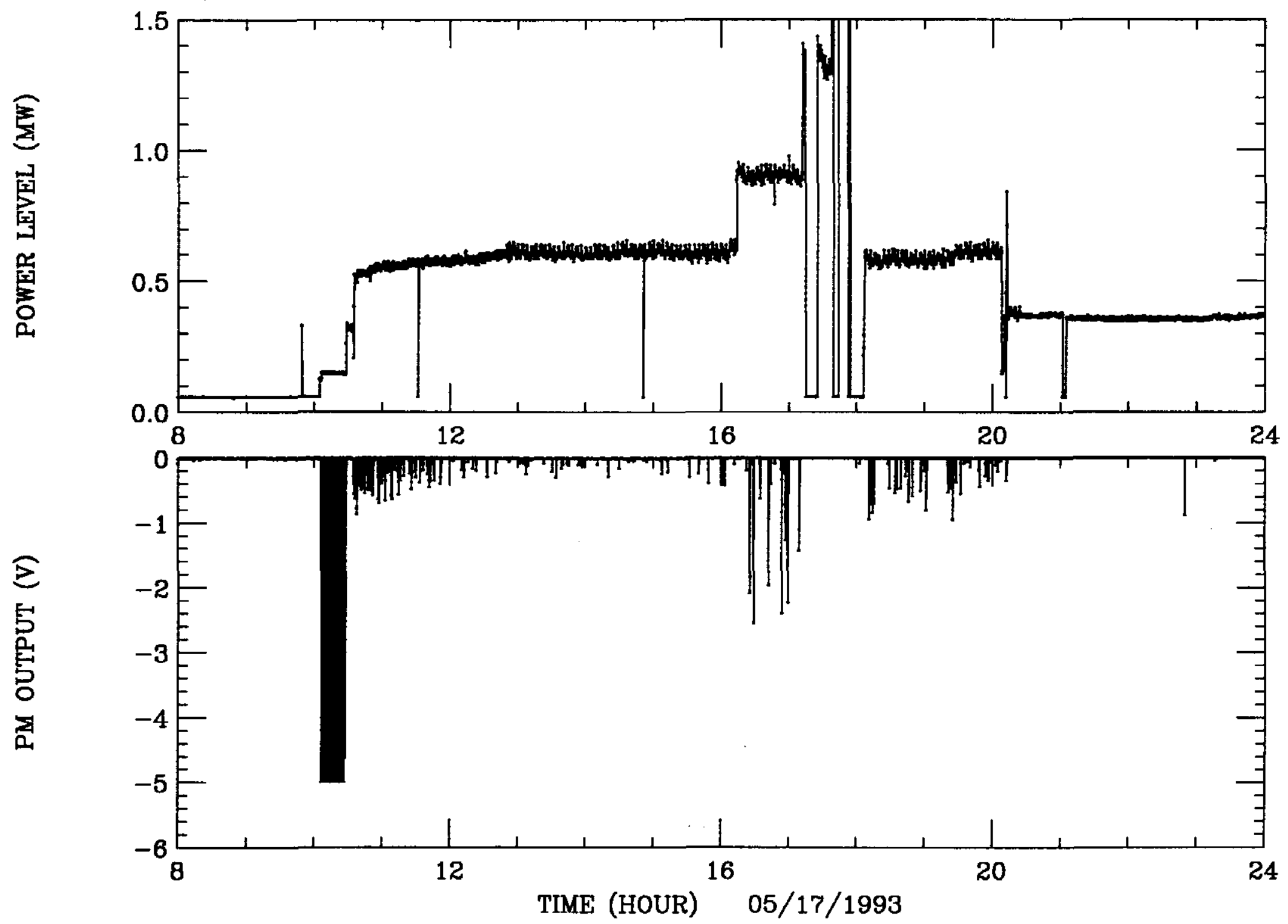

